ORIGINAL ARTICLE

\title{
Community acceptability of contraception after induced versus spontaneous miscarriage.
}

\author{
Zainab Maqsood', Majida Zafar², Syeda Batool Mazhar ${ }^{3}$, Khawar Sultan $^{4}$
}

Article Citation: Maqsood Z, Zafar M, Mazhar SB, Sultan K. Community acceptability of contraception after induced versus spontaneous miscarriage. Professional Med J 2022; 29(1):36-40. https://doi.org/10.29309/TPMJ/2022.29.01.6527

\begin{abstract}
Objective: To study the relationship between history of miscarriage (induced or spontaneous) and current use of modern contraceptive method among women in Pakistan. Study Design: Cross Sectional study. Setting: OPD of MCH, PIMS. Period: July 2019 to December 2019. Material \& Methods: A total of 80 married women were enrolled, 40 women who had induced miscarriage (group A) and 40 from spontaneous miscarriage (group B). Data is obtained on predesigned questionnaire. Primary outcome was acceptance of contraception (LARC) after induced versus spontaneous miscarriage. Results: About $51 \%$ of women were in the age group of 30-35 years and out of total 80 women, 67 (83\%) women had parity of three or above ( $27 \%$ had parity of three). Out of 66 women who used contraception, $35(53 \%)$ had induced miscarriage (group A) and 31 (46\%) had spontaneous miscarriage (group B). Women who belonged to induced miscarriage (group A) faced menstrual irregularity, as the reason of leaving contraception, followed by chronic PID and husband opposition. While in the group B, fertility desire was main reason of discontinuation of contraception. In Group A, 20 (50\%) women were willing to use LARC (long acting reversible contraception) after induced abortion to reduce the chances of unwanted pregnancy while in other group B, 15 (37.5\%) women were wanted to use LARC and 18 (45\%) women were not ready to use contraception due to fertility. Conclusion: High rate of induced abortion due to failed contraception and dis-continuation of contraceptives needs to be addressed by encouraging women to manage the side effects to ensure continuity of contraceptives.
\end{abstract}

Key words: $\quad$ Induced Miscarriage, Long Acting Reversible Contraception (LARC), Spontaneous Miscarriage.

\section{INTRODUCTION}

Women are often encouraged to use contraception after terminating a pregnancy in order to prevent future unwanted or undesirable pregnancies and subsequent abortions..$^{1,2,3}$ However many of these women could not avail contraception. Most of the times it was not easily accessible. About more than half of these pregnancies ended up in induced abortions. One third of world population lives in a country where induced abortion is not acceptable on request, or socioeconomic factors are not considered legal for induced abortion. ${ }^{8}$ Therefore, contraception provide birth control and prevention of unplanned pregnancies. ${ }^{7}$

Women who want to have a baby late called as "mistimed" and those who do not want to have pregnancy at all are called "unwanted pregnancy." Anxiety, denial and unawareness to the contraception use can lead to termination and result in serious complications, morbidity and mortality. ${ }^{4}$

Studies have shown that a key predictor of induced abortion is indicating that women are not getting access to modern methods of contraception after their first induced abortion to prevent another unwanted pregnancy. ${ }^{1,5}$ Other studies have shown that having an abortion may lead to increased use of contraception. ${ }^{1}$ Post-abortion care (PAC) should be legally available to all women, regardless of a country's abortion policies. ${ }^{1}$ Despite the improvement in contraception uptake, Pakistan contraception prevalence rate is only $34 \%$ according to PDHS 2018 , of which only $25 \%$ population uses modern
1. MBBS, Postgraduate Resident Gynecology and Obstetrics, PIMS Islamabad.

2. MBBS, FCPS, Assistant Professor Gynecology and Obstetrics, PIMS Islamabad.

3. MBBS, FCPS, Head of department Gynae/Ons PIMS Islamabad.

3. MD, Postgraduate Resident Nephrology, PIMS Islamabad.

\author{
Correspondence Address: \\ Dr. Zainab Maqsood \\ Department of Gynecology and obstetrics \\ PIMS Islamabad. \\ zainab_bhutta@yahoo.com \\ Article received on: \\ $14 / 04 / 2021$ \\ Accepted for publication: \\ $16 / 06 / 2021$
}


methods of contraception. ${ }^{6}$

Mixed evidence from these studies indicates a need for additional research to better understand whether women who have induced abortions in places where it is not widely available are getting the services they need to prevent future unintended pregnancies and repeat abortions.

The aim of the present study was to investigate the relationship between history of abortion (induced or spontaneous) and current use of a modern contraceptive method among women in Pakistan.

\section{MATERIAL \& METHODS}

This cross sectional study was conducted at Outpatient Clinic of MCH PIMS, Islamabad from July 1, 2019 to December 31, 2019.

The sample size was 80 patient. Non pregnant women from age 15 to 45 years who have history miscarriage before 24 weeks of pregnancy. Women who had miscarriage after 24 weeks.

After approval from ethical review board of SZABMU on $6^{\text {th }}$ June 2019 (F1-1/2019/ERB/ SZABMU) patients fulfilling selection criteria were divided into two groups. Group A women had history of induced miscarriage while group B women had spontaneous miscarriage. All patients were interviewed through a questionnaire containing socio-demographic details (age, patient occupation, husband occupation, patient income), reproductive profile, use of contraception method, side effects, reason of not using any contraception method, number of induced/spontaneous miscarriages and reason of induced abortion. Data were collected after obtaining informed consent. Primary outcome was acceptance of contraception (LARC) after induced verses spontaneous miscarriage. Data will be analyzed by descriptive analysis by SPSS 21.

\section{RESULTS}

About $51 \%$ of women were in the age group of 30-35 years and out of total 80 women, 67 (83\%) women had parity of three or above $(27 \%$ had parity of three). 31 (38.8\%) had 2 or more male and 1 female gender of alive children followed up by 21 (26.3\%) had 2 or more male children. 67 (83.8\%) women belonged to Muslim religion, 11 (13.8\%) were Christian and 2 (2.5\%) were Hindu. $73(91.3 \%)$ women were housewives, 5 (6.3\%) were teacher and 2 (2.5\%) were doing some private job. Majority of the women's husband 32 (40\%) were doing some private job and monthly income was around 20000 rupees. Out of total 80 women, 66 (82.5\%) used contraception. Out of 66 women who used contraception 35 (53\%) had induced miscarriage (group A) and 31 (46\%) had spontaneous miscarriage (group B). The most common method chosen was barrier method 39 (48.8\%), followed by pills/ injectables 16 (20.0\%), traditional methods $6(7.5 \%)$ and IUD/implanon 4 (5\%) [Table-I].

Of the total 80 women, 14 women (18.8\%) were not using any method of contraception. Remaining 66 women were asked about the correction of method and side effects with the use of contraceptive method. About $52.5 \%$ women were not practicing contraception method correctly. Majority 21 (26.3\%) women reported side effects of menstrual irregularity followed by $18(22.35 \%)$ reported vaginal discharge, lower abdominal pain $16(20.0 \%)$ and three (3.53\%) women had weight gain. Eight (10\%) women out of 66 reported no side effects of contraceptive method used. Reason of leaving contraception in this study were menstrual irregularity $23(28.8 \%)$, chronic PID 21 (26.3\%), fertility desire 12 (15\%), husband opposition 7 (8.8\%) and weight gain by $3(3.5 \%)$ women [Table-II]. Women who belonged to induced miscarriage (group A) faced menstrual irregularity, as the reason of leaving contraception, followed by chronic PID and husband opposition. While in the group $B$, fertility desire was main reason of discontinuation of contraception.

Around $72.5 \%$ (58) women had knowledge about contraceptive methods and majority belonged to group of spontaneous miscarriage. Similarly $77.5 \%$ women answered positively and majority belonged to spontaneous group.

Women who had induced miscarriage, the main 
reason was unwanted pregnancy in 25 (62.5\%) women out of 40 and financial issue in 15 (37.5\%) women. Interruption of pregnancy was mainly observed at gestational age less than 3 months in 41 (52.5\%) women in both groups (A \& B). Out of total 40 induced abortions, 24 (60\%) were conducted in private clinic and 16 at home.

These induced abortions were mainly conducted by LHV (Lady Health Visitor) 34 (85\%) followed by staff nurse 5 (12\%). In Group A, 20 (50\%) women were willing to use LARC after induced abortion to reduce the chances of unwanted pregnancy while in other group B, 15 (37.5\%) women wanted to use LARC and 18 (45\%) women were not ready to use contraception due to fertility desire [Figure-2]. Furthermore women were asked about abortion permissibility in religion, 64 (80\%) out of 80 women answered "NO" [Figure-1] and majority 38 (95\%) out of 40 women belonged to spontaneous miscarriage group.

\begin{tabular}{|l|c|c|}
\hline & Frequency & Percent \\
\hline No Method Used & 14 & $18.8 \%$ \\
\hline Traditional & 6 & $7.5 \%$ \\
\hline Barrier Method & 39 & $48.8 \%$ \\
\hline Pills/Injections & 16 & $20.0 \%$ \\
\hline IUD/Implanon & 4 & $5.0 \%$ \\
\hline Total & 80 & 100.0 \\
\hline \multicolumn{2}{|c|}{ Table-I. Prevalence of contraception. } \\
\hline
\end{tabular}

\begin{tabular}{|l|c|c|}
\hline \multicolumn{1}{|c|}{$\begin{array}{c}\text { Reason of Leaving } \\
\text { Contraception }\end{array}$} & Frequency & Percent \\
\hline No Contraception Used & 14 & $17.5 \%$ \\
\hline Fertility Desire & 12 & $15.0 \%$ \\
\hline Menstural Irregularity & 23 & $28.8 \%$ \\
\hline Valid Weight Gain & 3 & $3.7 \%$ \\
\hline Chronic PID & 21 & $26.3 \%$ \\
\hline Husband Opposed & 7 & $8.7 \%$ \\
\hline Total & 80 & $100.0 \%$ \\
\hline
\end{tabular}

Table-II. Reason of leaving contraception.

\section{DISCUSSION}

Family planning in a society forms a vital component of modernization and much needed for the incorporation of women into social and economic life. In our study, the maximum number of women (51\%) were aged between 30 and
35 years. In another study maximum women belonged to age group 25 and 34 years. ${ }^{9}$ Majority women who participated in the study were Muslim as this study was conducted in a Muslim country. Women who participated in the study had parity of three or more and $38.8 \%$ had 2 or more male children.

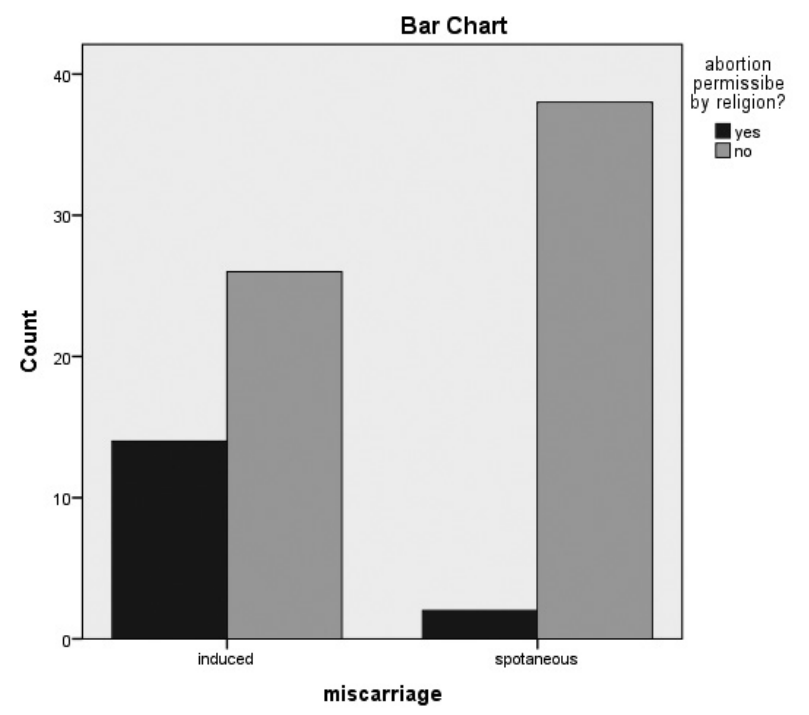

Figure-1. Permissibility of abortion by religion in induced VS spontaneous miscarriage.

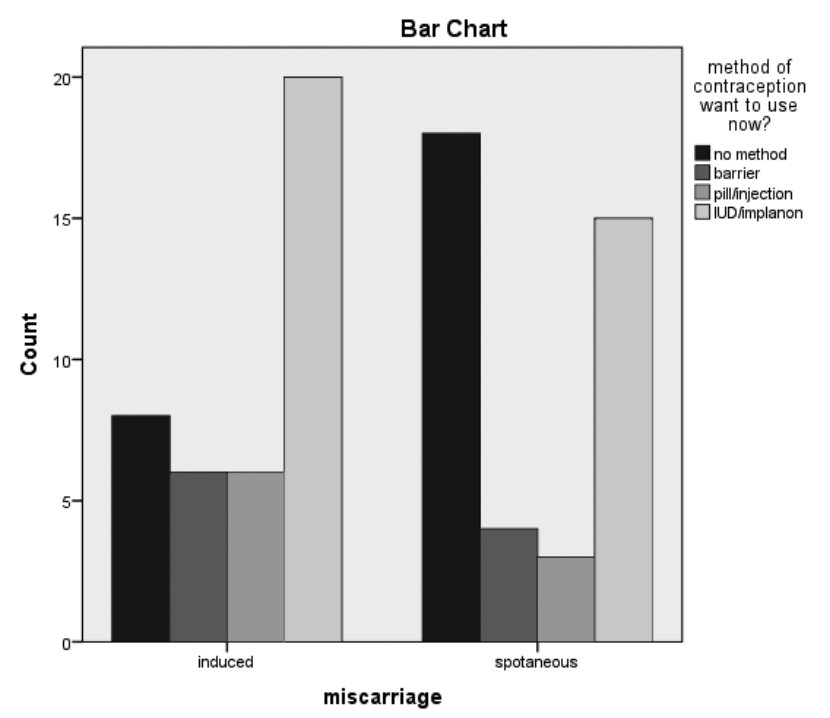

Figure-2. Use of contraceptive method after miscarriage (induce VS spontaneous).

Majority women $91.3 \%$ were not working outside the home which is comparable to Iran study where $87.1 \%$ of the participants were not involved in any job. ${ }^{9}$ In our study $88 \%$ women were educated atleast till secondary level comparing 
it to Iran study, where $40-79.2 \%$ women were graduated. According to $\mathrm{PDHS}^{6}$ survey 201718 contraception prevalence rate is $34 \%$ in our country while in our study it was $82 \%$, either contraceptive method used once in their life or for longer period of time.

In our study $72 \%$ women had awareness of contraceptive method and also know about their availability. Comparing it with other study, up to $91.0 \%$ women were aware of contraceptive methods ${ }^{7}$. This is comparable to $81 \%$ in a national study conducted in the rural area of Sindh by Mustafa et $\mathrm{al}^{11}$ and $91.4 \%$ seen in International study conducted in Jordan. ${ }^{12}$ Our study found no relationship between level of education and use of contraception but it was directly related to awareness of contraception.

Occurrence of atleast one life time abortion was $45.7 \%$ in $\operatorname{Iran}^{9}$, while in our study, it was quite high $67.5 \%$. Most of the miscarriages were in $1^{\text {st }}$ trimester $52.5 \%$ which is comparable to a study conducted in Zombie which showed 59\% women had miscarriages between 7-12 weeks of gestation. Uncertainty of sign and symptoms of miscarriage, lower abdominal pain and vaginal bleeding could be the reason.

In our study $18 \%$ women did not use any kind of contraception. Most common method used for contraception was barrier method $48 \%$ followed by injectables $20 \%$. In contrast to a local study conducted in Pakistan by Jabeen et $\mathrm{al}^{13} 69.20 \%$ were not using any contraception method. Traditional methods (withdrawal and rhythm methods) were the commonest method of contraception among 5.9\% women, followed by injectable (5.3\%) and tubal ligation $(5.1 \%) .{ }^{13}$ While a study conducted in India by Sharma et $\mathrm{al}^{4}$ showed that the use of contraceptive was $73.28 \%$ and condom/barrier (24.13\%) was the commonest method used. Most common side effect of contraception was menstrual irregularity in $26 \%$ followed by vaginal discharge in $22 \%$, lower abdominal pain in $20 \%$ and weight gain in $3.8 \%$ women in our study. Similar results were shown by Jabeen et $\mathrm{al}^{4}$ in which menstrual disturbance was observed by $23.80 \%$ women, and weight gain in $11.19 \%$ women.

In our study menstrual irregularity $26 \%$ was the main reason of leaving contraception, after that was fertility desire in 15\%. In contrast, fertilityrelated reasons were found as the main reasons for leaving contraception in studies by Das et al. ${ }^{14}(38.9 \%)$, Khokhar and Mehra ${ }^{15}(30.7 \%)$, and Bhasin et al. ${ }^{16}$ (36.4\%). Other studies mentioned opposition by family as the biggest reason for the non-use of contraception. ${ }^{17,18}$ Out of all the women with induced abortion, 50\% accepted LARC as a method of contraception to avoid future induced abortion. Which is comparable to the high acceptability of LARC in a study conducted by china where $42.5 \%$ women were intended to use LARC after induce abortion. ${ }^{10}$

As our study was having limited data, large sample size can give more reliable results so that appropriate interventions can be done.

\section{CONCLUSION}

High rate of induced abortion due to failed contraception and dis-continuation of contraception needs to be addressed by encouraging women to ensure continuity of contraceptives. Long acting reversible contraception (LARC) is the way forward to avoid complications of induced abortion.

\section{Copyright $(\subset) 16$ June, 2021.}

\section{REFERENCES}

1. Morris N, Prata N. Abortion history and its association with current use of modern contraceptive methods in Luanda, Angola. Open Access Journal of Contraception. 2018; 9: 45-55

2. Padmadas SS, Lyons-Amos M, Thapa S. Contraceptive behavior among women after abortion in Nepal. Int $\mathrm{J}$ Gynecol Obstet. 2017; 127:132-7.

3. Sedlecky K, Stanković Z. Contraception for adolescents after abortion. Eur J Contracept Reprod Health Care. 2016; 21:4-14.

4. Sharma A, Sharma $U$, Acharya R, Chaudhary $P$, Chaudhary A. Acceptability and practice of contraception and frequency of induced abortions in married women of reproductive age group, in a tertiary-care hospital. Int $\mathrm{J}$ Med Sci Public Health 2015; 4: 845-8. 
5. Benson J, Andersen K, Samandari G. Reductions in abortion-related mortality following policy reform: Evidence from Romania, South Africa and Bangladesh. Reprod Health 2011; 8: 39.

6. Pakistan demographic and health survey (PDHS) 2017- 2018.

7. Mazhar SM, Mazhar SB, Ghumman SS. Knowledge, attitude and practices of contraception and intergenerational differences among married women in rural Islamabad. J Soc Obstet Gynaecol Pak. 2015; 5(3):145-50.

8. Rasch V, Massawe S, Yambesi F, Bergstrom S. Acceptance of contraception among women who had an unsafe abortion in dar e salaam. 2004; 9(3): 399-405.

9. Nojomi M, Akbarian A, Ashory-Moghadam S. Burden of abortion: Induced and spontaneous Arch Iranian Med 2006; 9 (1): 39 - 45.

10. Luo Z, Gao L, Anguzu R, Zhao J. Long-acting reversible contraceptive use in the post-abortion period among women seeking abortion in mainland China: Intentions and barriers. Reproductive health. 2018 Dec; 15(1):1-9.

11. Mustafa R, Afreen $U$ and Hashmi HA. Contraceptive knowledge, attitude and practice among rural women. J Coll Physicians Surg Pak. 2008; 18(9):54245.
12. Mahadeen Al, Khalil AO, Hamdan-mansour AM, Sato T, Imoto $A$. Knowledge, attitude and practices towards family planning among women in the rural southern region of Jordan. East Mediterr Health J. 2012; 18(6): 567-72.

13. Jabeen M, Gul F, Wazir F, Javed N. Knowledge, attitude and practices of contraception in women of reproductive age. Gomal J Med Sci. 2011; 9(2): 22329.

14. Das R, Amir A, Nath P. Utilisation and coverage of services by women of Jawan Block in Aligarh. Indian J Community Med 2001; 26(2):94-100.

15. Khokhar A, Mehra M. Contraceptive use in women from resettlement area in Delhi. Indian $\mathrm{J}$ Community Med 2005; 30(1):21-3.

16. Bhasin SK, Pant M, Metha M, Kumar S. Prevalence of usage of different contraceptive methods in East Delhi: A cross sectional study. Indian J Community Med 2005; 30(2):53-5.

17. Jain S, Singh JV, Bhatnagar M, Garg SK, Chopra $H$, Bajpai SK. Attitude of rural women towards contraceptive and its use. Indian J Matern Child Health 1999; 10(1):18-9.

18. Dhillon BS, Chandhiok N, Kambo I, Saxena NC. Induced abortion and concurrent adoption of contraception in rural areas of India (an ICMR task force study). Indian J Med Sci 2004; 58(11):478-84.

\begin{tabular}{|c|c|c|c|}
\hline \multicolumn{4}{|c|}{ AUTHORSHIP AND CONTRIBUTION DECLARATION } \\
\hline No. & Author(s) Full Name & Contribution to the paper & Author(s) Signature \\
\hline 1 & $\begin{array}{l}\text { Zainab Maqsood } \\
\text { Majida Zafar }\end{array}$ & $\begin{array}{l}\text { Author, Research conception, } \\
\text { Data collection, Correspondent. } \\
\text { Review and proof reading. }\end{array}$ & \\
\hline 3 & $\begin{array}{l}\text { Syeda Batool Mazhar } \\
\text { Khawar Sultan }\end{array}$ & $\begin{array}{l}\text { Research concept and critical } \\
\text { evaluation. } \\
\text { Statistical modeling. }\end{array}$ & \\
\hline
\end{tabular}

